\title{
Recovery of Rare Earth Elements Present in Mining Tails, by Leaching with Nitric and Hydrochloric Solutions
}

\author{
Peter Fleming*, Pedro Orrego, Felipe Pinilla \\ Nuclear Research and Applications Division, Chilean Nuclear Energy Commission, Santiago, Chile \\ Email: ^Peter.fleming@cchen.cl
}

How to cite this paper: Fleming, P., Orrego, P. and Pinilla, F. (2021) Recovery of Rare Earth Elements Present in Mining Tails, by Leaching with Nitric and Hydrochloric Solutions. World Journal of Nuclear Science and Technology, 11, 1-16.

https://doi.org/10.4236/wjnst.2021.111001

Received: September 28, 2020

Accepted: January 8, 2021

Published: January 11, 2021

Copyright $\odot 2021$ by author(s) and Scientific Research Publishing Inc. This work is licensed under the Creative Commons Attribution International License (CC BY 4.0).

http://creativecommons.org/licenses/by/4.0/

\begin{abstract}
The rare earth elements (REE) include the group of 15 lanthanides, scandium and yttrium and have diverse applications in technological and nuclear areas. The existence of REE in massive solid mining wastes generated in leaching processes of copper minerals in the Atacama region of Chile generates the possibility of creating added value to the treatment of this type of waste and supporting the development of a circular economy, generating a useful by-product in different industries. In order to know the behavior of these elements present in the solid carrier waste, a leaching process was carried out by using two agents separately, corresponding to hydrochloric and nitric acid. The technical feasibility to recover REE from carrier tail was demonstrated, the best leaching agent for these elements being a hydrochloric solution, obtaining a maximum recovery efficiency of $64.5 \%$, for an acid concentration: $3 \mathrm{M}$, temperature: $40^{\circ} \mathrm{C}$ and (liquid/solid) ratio: 4 . Lanthanum and cerium present the best individual recoveries compared to the other REE, with a maximum efficiency for a hydrochloric solution of $75.7 \%$ and $70.0 \%$, respectively. The interaction of operational parameters that most influence the REE recovery corresponds to the temperature and the (liquid/solid) ratio. After 4 hours of leaching, REE recovery efficiencies remain practically constant. Acid consumptions correspond to 11 ( $\mathrm{kg} \mathrm{HCl} /$ ton mining tail) and $29\left(\mathrm{~kg} \mathrm{HNO}_{3} /\right.$ ton mining tail). The highest amount recovery ratios of these elements correspond to 0.355 and 0.224 (kg REE/ton mining tail), for hydrochloric and nitric solutions, respectively. These results influence the types of reagents and parameters to be studied in the following stages of the global process.
\end{abstract}

\section{Keywords}

Rare Earth Elements, Leaching, Solid Mining Waste, Mining Tail 


\section{Introduction}

Rare Earth Elements (REE) include the lanthanide series of the periodic table, from atomic number 57 to 71, starting with Lanthanum (La) to Lutetium (Lu) and including scandium $(\mathrm{Sc})$ and yttrium $(\mathrm{Y})$, whose atomic numbers are 21 and 39 , respectively, which, although they do not have 4 f electrons, are closely related to them and usually occur in the natural state associated with lanthanides [1].

REE shows chemical similarities and unique electronic, optical, luminescent, and magnetic properties in comparison to the other metals in the periodic table. Nowadays, these physicochemical properties are utilized in a wide range of synthetic, catalytic, electronic, medicinal, nuclear and military applications. Thus, the REE are present in a multitude of devices such as computers, cell phones, and televisions. In addition, these elements are used in automotive catalytic converters, petroleum refining, lasers, fuel cells, light-emitting diodes, magnetic resonance imaging (MRI), hybrid electric vehicles, solar energy, and windmills, among others [2] [3].

Considering their large capture cross-sections for thermal neutrons; that is, they absorb a large number of neutrons per unit area, such as natural samarium, europium, gadolinium and dysprosium. Some of these elements are incorporated into the control rods that are used to regulate the operation of nuclear reactors, such as europium and dysprosium, or to turn them off if they get out of control, such as gadolinium. Additionally, to increase the operating temperature of a reactor, the melting point and the mechanical properties of the fuel must be increased, resorting in some cases to metallic alloys of these elements, in addition, for a fuel rich in actinides, yttrium can be added, lanthanum or other rare earth elements, such as stabilizers [4].

\subsection{REE in Chilean Ores}

In Chile, some areas with presence of these elements have been identified, through the uses of geochemical, radiometric and aerospectrometric techniques and analysis. One of these zones corresponds to Cerro Carmen, located in the Atacama region, close to Diego de Almagro city. A representative mineral sample from this area was characterized by the presence of potassium feldspars and plagioclase feldspars stained with limonites, in addition, it presents a uniform and disseminated metallic mineralization with sizes between 1 to $5(\mathrm{~mm})$, it also presents magnetite, hematite and contributions of new elements by crystals of sphene, ilmenite or zircon. Associated with minerals included in the group of "Radioactive Complex Oxides of Fe, Ti, U, Th and REE", Figure 1 [5] [6].

\subsection{Leaching Technique}

The leaching technique is highly used in the treatment of copper oxide ores and has the definition "to treat a complex substance, such as a mineral, with a suitable solvent to separate its soluble from the insoluble parts". There are different types of leaching, one of them is "agitation leaching", are used mostly in high-grade 


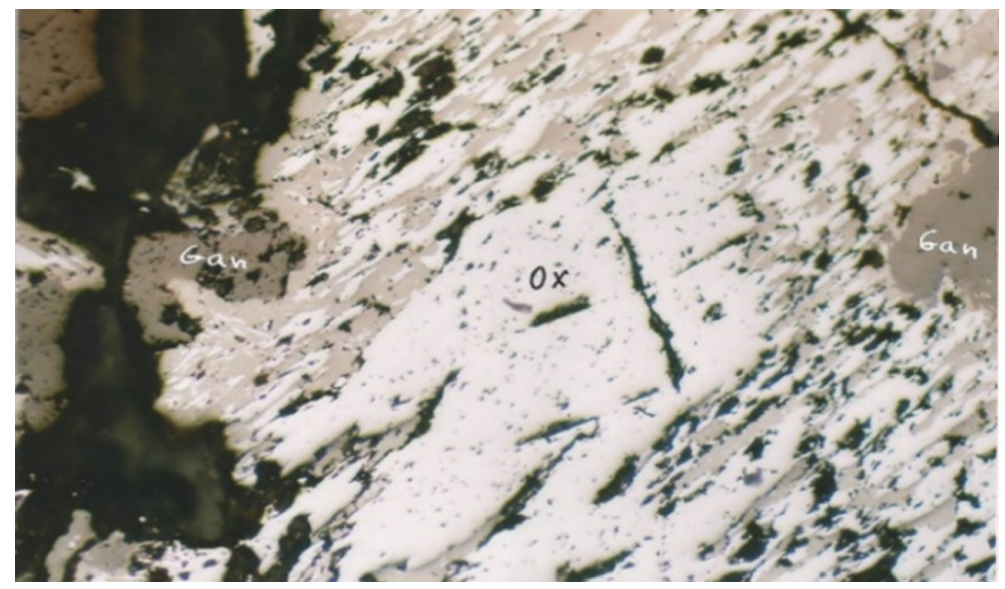

Figure 1. Polished cut. $5 \times 10$ magnification. Nicoles Parallels. Scale $1 \mathrm{~cm}=200$ microns.

minerals, when a large amount of fine is generated by the crushing stage or if the mineral is so widespread that a grinding stage is required to achieve a greater exposure of the particles to the leaching solution. It is possible to carry it out by mechanical agitation, where the agitation in the pond is achieved by means of an impeller, driven by an electric motor, producing a constant and uniform agitation. There are different types of impeller, to name a few, there is that of vanes, blades, turbines, propellers, among others. The disadvantage is that if the speed of rotation is not controlled, it can affect the dissolution of the mineral, so baffles are often used to prevent the rotational flow lines, without interfering with the final product. The advantage lies in the feasibility of using various factors that accelerate the dissolution kinetics, such as intense agitation, good gas control, high temperatures $\left(<250^{\circ} \mathrm{C}\right)$, controlled handling of reagents, oxidants and others, which makes it the most used option when it comes to agitation leaching [7] [8] [9].

\subsection{Leaching Chemical Reactions}

The leaching of mining tail involves various chemical reactions, mainly involved in the dissolution of elements from solid to liquid state, it depends on the type of leaching solution. The main reactions of interest for REE with hydrochloric and nitric solutions, are the following:

$$
\begin{gathered}
(\mathrm{REE})_{2} \mathrm{O}_{3}+6 \mathrm{HCl} \rightarrow 2(\mathrm{REE}) \mathrm{Cl}_{3}+3 \mathrm{H}_{2} \mathrm{O} \\
(\mathrm{REE})_{2} \mathrm{O}_{3}+6 \mathrm{HNO}_{3} \rightarrow 2(\mathrm{REE})\left(\mathrm{NO}_{3}\right)_{3}+3 \mathrm{H}_{2} \mathrm{O}
\end{gathered}
$$

In addition, the high presence of iron interferes with the subsequent solvent extraction process, so it is necessary to consider the following reactions:

$$
\begin{gathered}
\mathrm{FeO}+2 \mathrm{HCl} \rightarrow \mathrm{FeCl}_{2}+\mathrm{H}_{2} \mathrm{O} \\
\mathrm{Fe}_{2} \mathrm{O}_{3}+6 \mathrm{HCl} \rightarrow 2 \mathrm{FeCl}_{3}+3 \mathrm{H}_{2} \mathrm{O} \\
\mathrm{FeO}+2 \mathrm{HNO}_{3} \rightarrow \mathrm{Fe}\left(\mathrm{NO}_{3}\right)_{2}+\mathrm{H}_{2} \mathrm{O} \\
\mathrm{Fe}_{2} \mathrm{O}_{3}+6 \mathrm{HNO}_{3} \rightarrow 2 \mathrm{Fe}\left(\mathrm{NO}_{3}\right)_{3}+3 \mathrm{H}_{2} \mathrm{O}
\end{gathered}
$$




\section{Experimental Procedure}

The main objective of this research is to know the behavior of REE contained in mining tails generated in the sulfuric leaching of Cerro Carmen ore, corresponding to mining tail 1 in Figure 2, by implementing a batch system, Figure 3 .

The residue that will be obtained from this stage is mining tail 2. After the leaching stage, the obtained Pregnant Leach Solution (PLS) will be subjected to the solvent extraction technique, to purify and concentrate the solution containing REE, to subsequently implement the precipitation step generating a compound of these elements, which will be calcined to obtain a concentrate of REE oxide.

In order to determine the best efficiency in the recovery of REE from its matrix, the following operational parameters were studied, which, in addition,

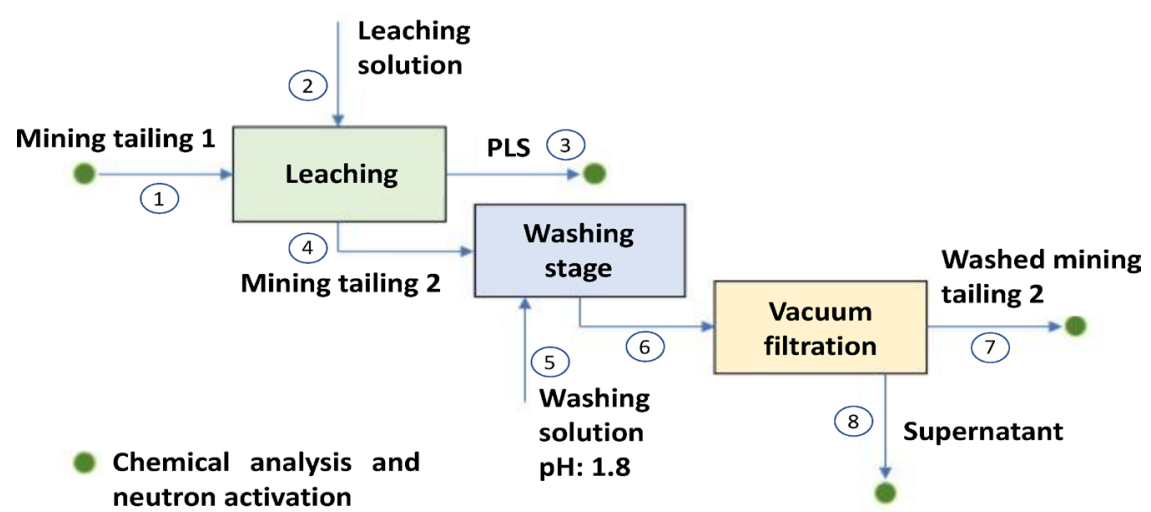

Figure 2. Mining tail leaching process diagram.

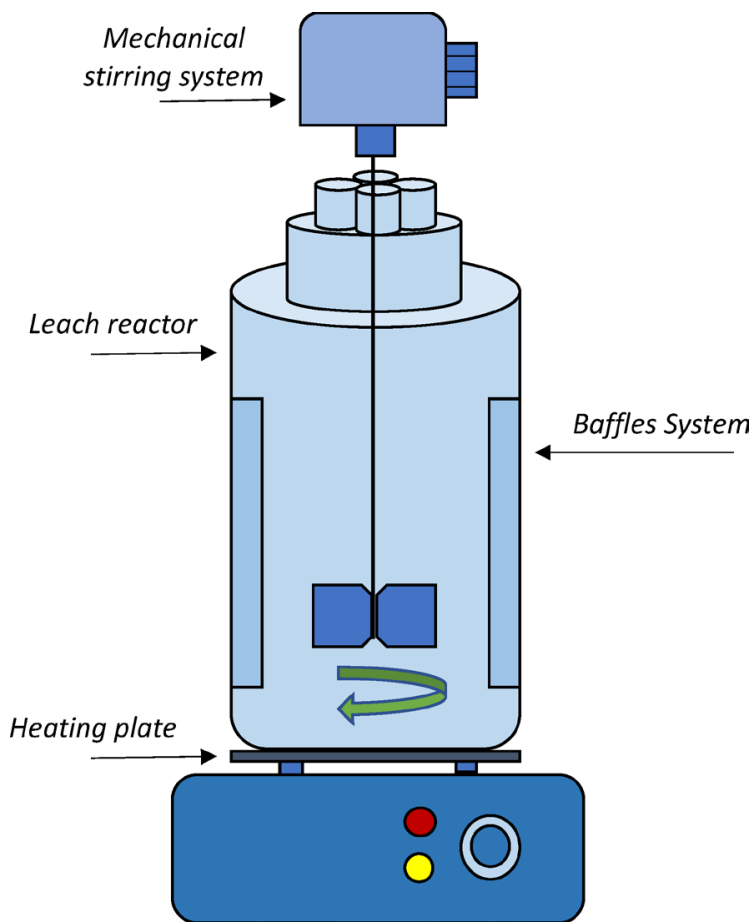

Figure 3. Batch leaching system. 
significantly influence the operating costs: System temperature, leaching ratio solid/liquid (S/L), acid concentration of the leaching solution. Three sets of 8 experiences each one were developed, according to experimental model $2^{\mathrm{k}}$ methodology, with $\mathrm{k}=3$ [10] [11].

The tests were carried out inside a glass reactor, by mechanical agitation, batch system, heated using a heating plate.

The batch leaching procedure for mining tail 1 is described in Figure 4, and generally consists of: empty the acid solution inside the reactor with baffle system to prevent the rotational flow lines, without interfering with the final product, turn on the agitation system (200 RPM) and heating, when reaching the required temperature the mining tail 1 is poured slowly, the agitation system is increased to 500 RPM, maintaining the system with constant operational parameter values for a period of 6 hours.

Once the process is finished, the pulp is filtered by vacuum filter, separating the PLS from the mining tail 2, which was washed with an acid solution at $\mathrm{pH}=$ 1.8 and a ratio $(\mathrm{S} / \mathrm{L})=1$, in order to eliminate any drag of acid leaching solution in mining tail 2. Once the process is finished, homogeneous solid and liquid samples are obtained for their chemical characterization.

Additionally, ISO-pH test, known as rolled bottle leaching test, was carried out in order to determine the consumption of acid per treated mining tail, Figure 5 .

\section{Results and Discussion}

\subsection{Physical Characterization, Mining Tail 1}

It is worth mentioning that the mining tail 1 was previously homogenized to obtain representative results. The density was determined by the pycnometric method and natural humidity through the method described in the ASTM-D2216 standard. The results are: density: $2.3175\left(\mathrm{~g} / \mathrm{cm}^{3}\right)$, natural humidity: $30 \%$ and the particle size distribution corresponds to: $d_{10}: 10.6(\mu \mathrm{m}), d_{50}: 59.7(\mu \mathrm{m}), d_{90}: 250$ $(\mu \mathrm{m})$, with an average of $103(\mu \mathrm{m})$, Figure 6.

\subsection{Chemical Characterization, Mining Tail 1}

The concentration of the elements of interest present in the mining tail 1 are reported in Table 1, showing that the highest concentrations are for the elements Sc, Y, La and Ce, with a total REE concentration of $579.8 \mathrm{ppm}$. Additionally, there is the presence of other elements that can interfere with the selectivity and efficiencies of the process, one of the most relevant being iron, with a concentration of 21,000 (ppm).

\subsection{Iso-pH Test}

The purpose of these tests is to know the general consumption of acid by the mining tail 1 . The implemented system corresponds to a roller agitator, where a pulp of ore was treated in bottles of 10 liters each one, measuring the $\mathrm{pH}$ of the 


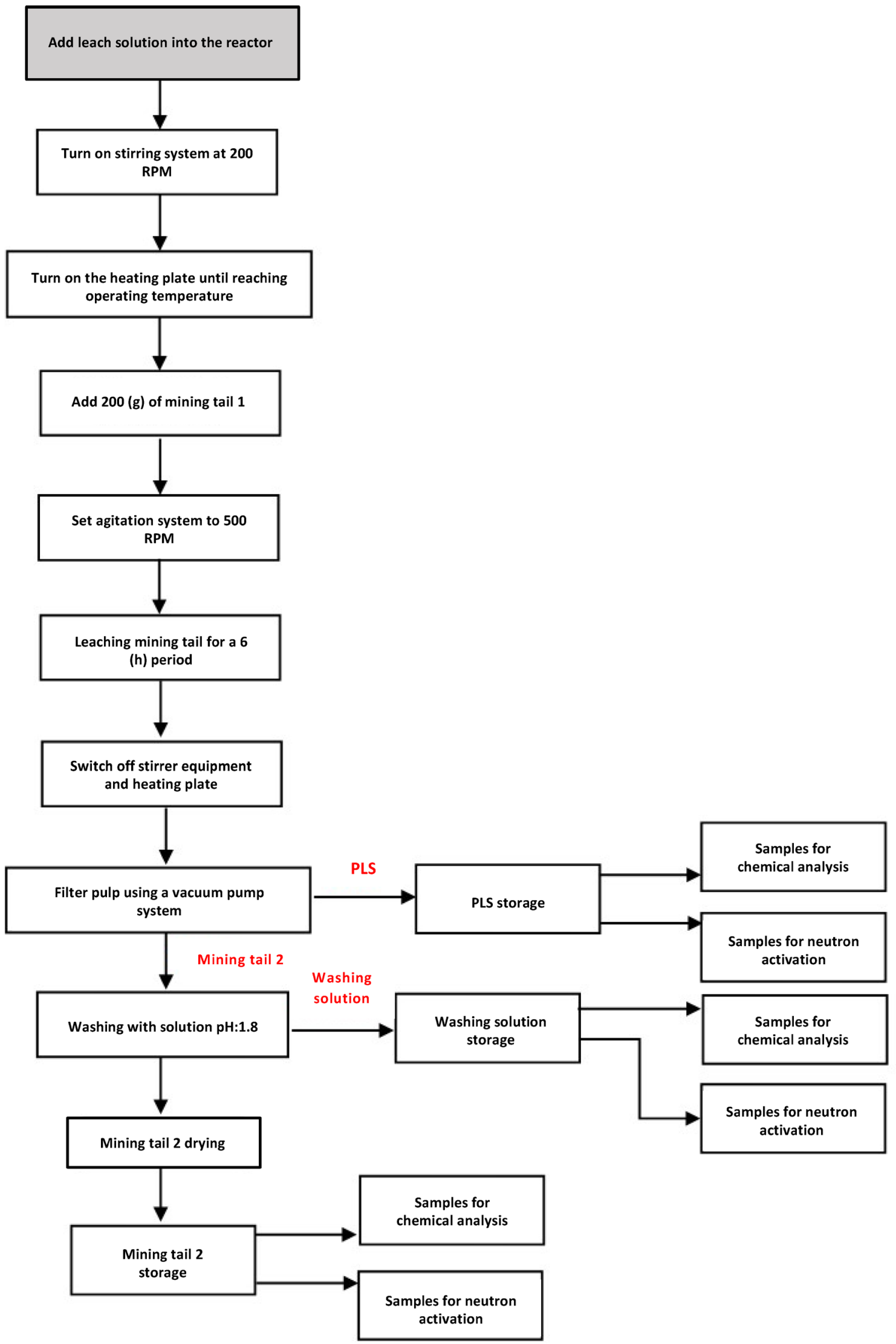

Figure 4. Batch leaching procedure. 


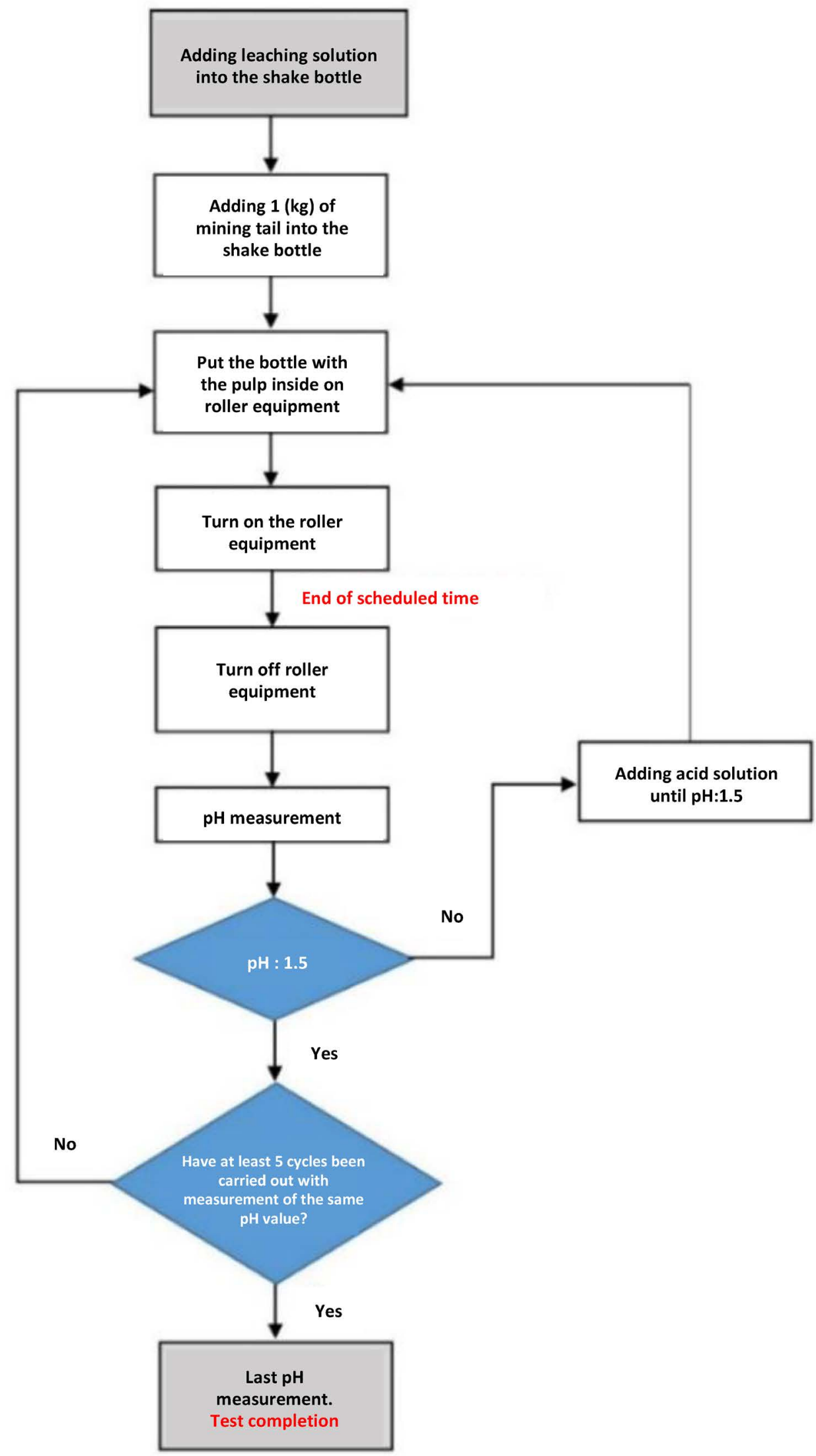

Figure 5. Rolled bottle leaching test procedure. 


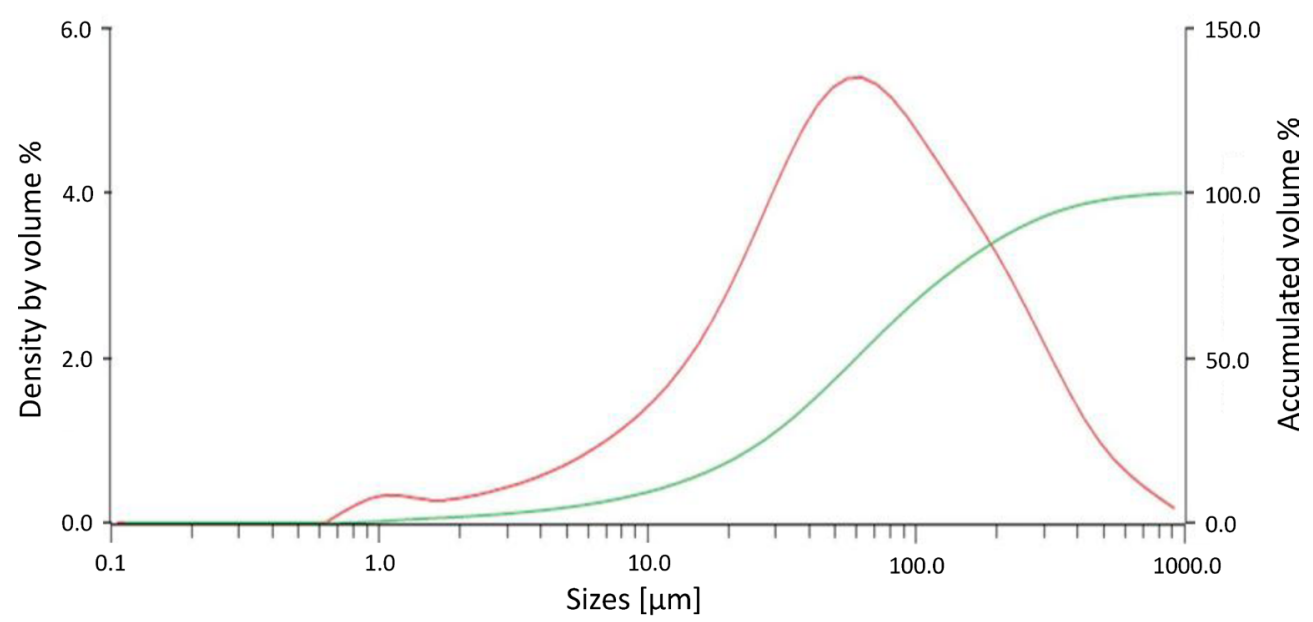

Figure 6. Density by volume and accumulated volume regarding different sizes. Frequency (compatible-red color) and accumulated (green color).

Table 1. Rare earth elements concentration (ppm), mining tail 1.

\begin{tabular}{cccccccccc}
\hline & \multicolumn{8}{c}{ REE concentration (ppm); mining tail 1 } \\
\hline Element & $\mathrm{Sc}$ & $\mathrm{Y}$ & $\mathrm{La}$ & $\mathrm{Ce}$ & $\mathrm{Pr}$ & $\mathrm{Nd}$ & $\mathrm{Sm}$ & $\mathrm{Eu}$ & $\mathrm{Gd}$ \\
\hline Concentration & 65.8 & 92.0 & 156.1 & 154.0 & 9.0 & 21.2 & 4.0 & 1.0 & 7.1 \\
\hline Element & $\mathrm{Tb}$ & $\mathrm{Dy}$ & $\mathrm{Ho}$ & $\mathrm{Er}$ & $\mathrm{Tm}$ & $\mathrm{Yb}$ & $\mathrm{Lu}$ & $\mathrm{REE}$ total & \\
\hline Concentration & 2.0 & 14.7 & 4.0 & 17.2 & 3.0 & 25.8 & 3.0 & 579.8 & \\
\hline
\end{tabular}

solution in different time intervals, until reaching a constant value in an acceptable time range. Both acid solutions were used separately, considering a reference $\mathrm{pH}=1.5$. The results obtained indicate that acid consumptions for hydrochloric and nitric solutions were $11(\mathrm{~kg} \mathrm{HCl} /$ ton mining tail 1$)$ and $29(\mathrm{~kg}$ $\mathrm{HNO}_{3}$ /ton mining tail 1), respectively. In Figure 7, it is possible to observe that after 6 (h) the acid consumption in both cases remains constant, furthermore, consumption is significantly higher in the case of a nitric solution, being a factor of 2.64 .

\subsection{Leaching Test}

The main results of the acid leaching tests by applying a mechanical stirring system are informed below, these were obtained through a set of experiences of the type $2^{3}$ experimental model, for the two acids used. It is worth mentioning that the values of the operational parameters studied are those corresponding to $\mathrm{Ta}$ ble 2 .

\section{Hydrochloric solution}

The recovery efficiencies for total REE are reported in Figure 8, in addition, the results of the elements with the highest presence in the mining tail 1 , corresponding to $\mathrm{Sc}, \mathrm{Y}, \mathrm{La}$ and $\mathrm{Ce}$, being more significant for the total result. It is possible to observe that the REE recovery efficiencies are higher for the $\mathrm{ABC}$ test, that is, considering the highest values of the operational parameters. The 


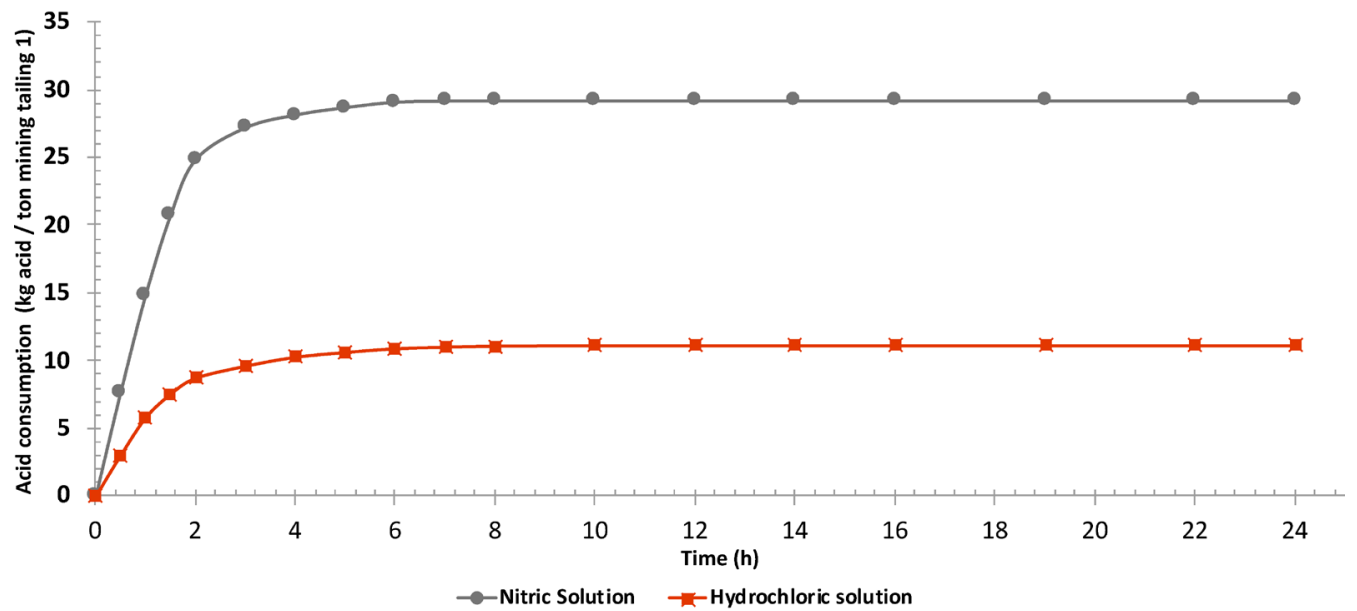

Figure 7. Acid consumption over time (Iso-pH test).

Table 2. Leaching test matrix.

\begin{tabular}{cccc}
\hline \multirow{3}{*}{ Exp } & \multicolumn{3}{c}{ Leaching Test Matrix } \\
\cline { 2 - 4 } & Acid concentration (M) & Temperature $\left({ }^{\circ} \mathrm{C}\right)$ & Ratio $(\mathrm{L} / \mathrm{S})$ \\
\hline $\mathbf{1}$ & 1 & 25 & 2 \\
A & 3 & 25 & 2 \\
B & 1 & 40 & 2 \\
AB & 3 & 40 & 2 \\
C & 1 & 25 & 4 \\
AC & 3 & 25 & 4 \\
BC & 1 & 40 & 4 \\
ABC & 3 & 40 & 4 \\
\hline
\end{tabular}

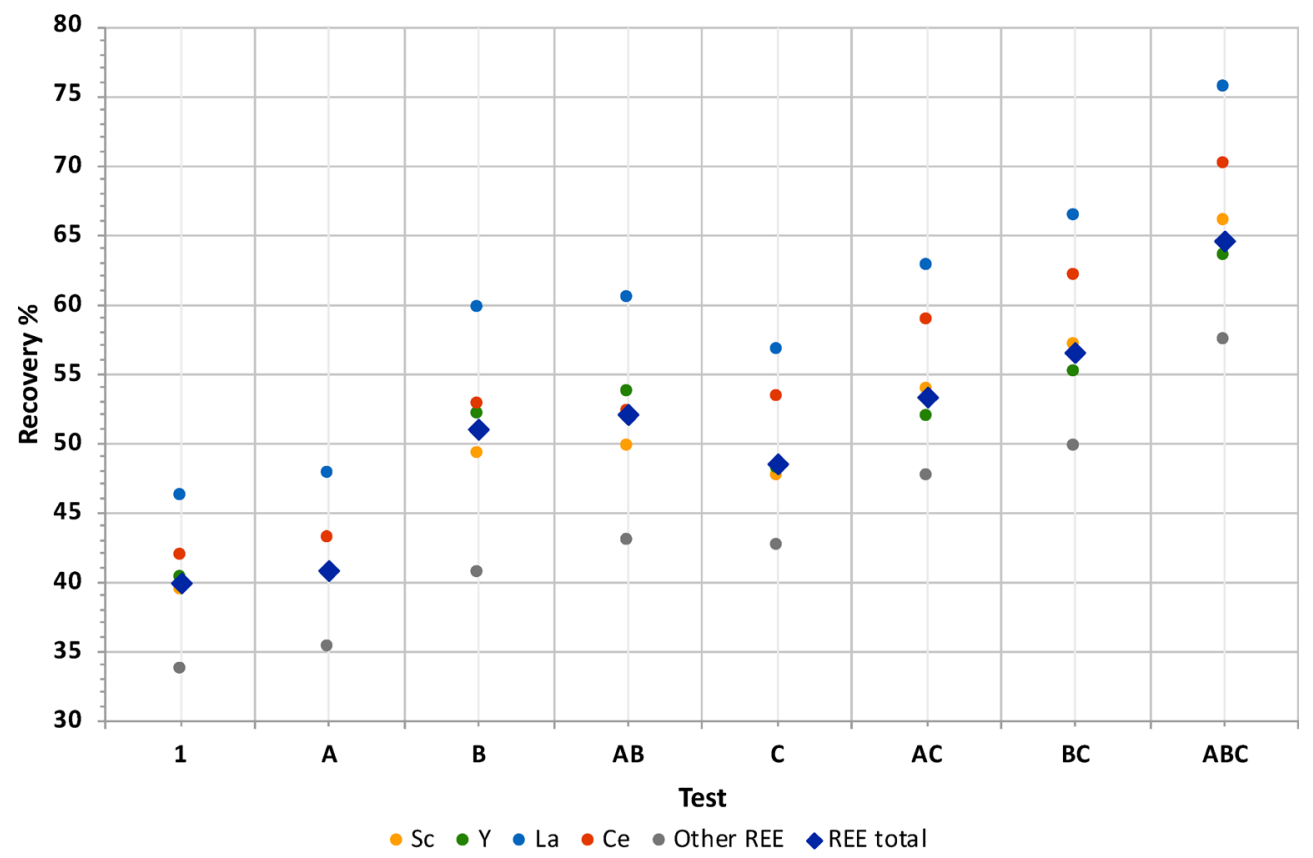

Figure 8. REE recovery efficiencies from mining tail 1, by leaching with hydrochloric solution. 
maximum global recovery of REE was $64.5 \%$. Regarding the significant elements, the one with the best recoveries corresponds to $\mathrm{La}$ and $\mathrm{Ce}$, with a maximum efficiency of $75.7 \%$ and $70.0 \%$, respectively. For $\mathrm{Y}$ and Sc, the results are close to the total REE in all test combinations.

Additionally, the influence of the main effects was determined separately, Figure 9, where it is possible to observe that the factors that present a greater influence within the total REE recovery efficiencies correspond to temperature, which possibly is due to the fact that the dissolution kinetics of these elements in the leaching solution increases considerably and, in the same way, the (L/S) ratio, which has a high influence on the recovery for a ratio: 4 , possibly due to the fact that there is a distribution of the mining tail particles within the leaching solution, which increases the contact area of these with the acid molecules. The operating parameter with the least influence corresponds to the acid concentration, independent of the fact that as it increases, the recovery efficiency does so in a lower percentage. Regarding the interaction of the main effects for the recovery of total REE, Figure 10, it is possible to observe that the interaction between $(\mathrm{L} / \mathrm{S})$ ratio and temperature is the one that presents a greater increase in efficiency, for the conditions (L/S) ratio: 4 and temperature: $40^{\circ} \mathrm{C}$. Table 3 shows the REE concentrations of the PLS obtained in ABC test, with the best recovery efficiency.

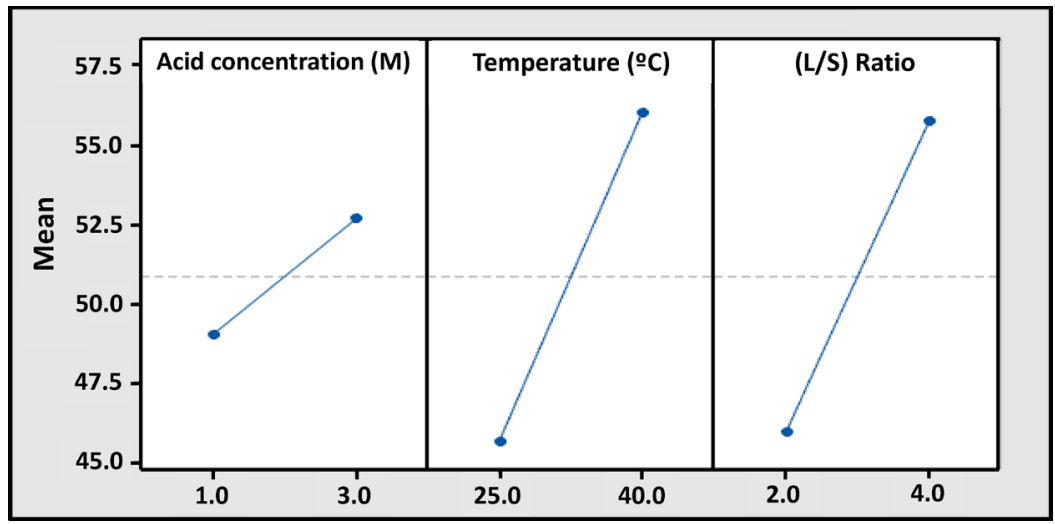

Figure 9. Individual factor effect in REE total recovery, hydrochloric solution.

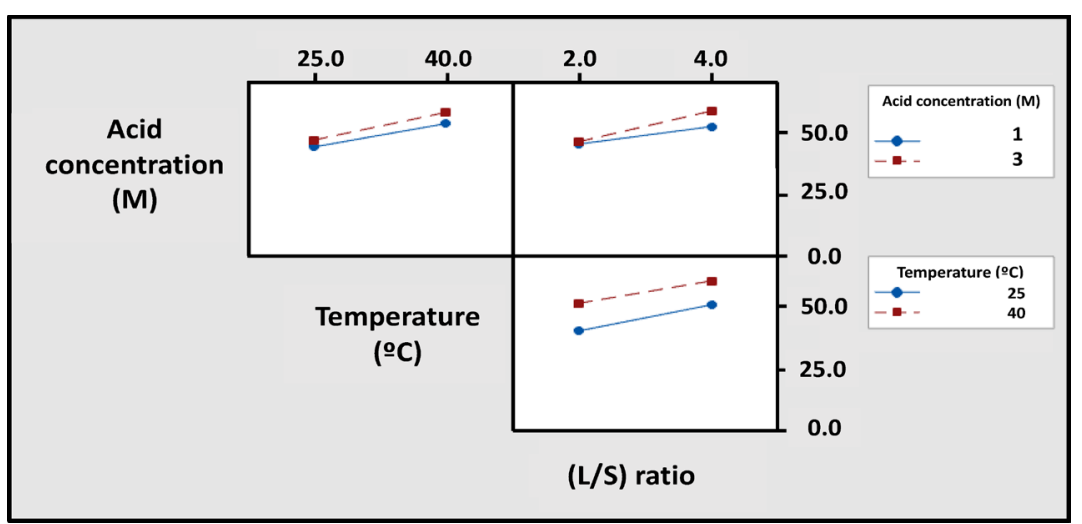

Figure 10. Interaction of main effects in total REE efficiency recovery, hydrochloric solution. 


\section{Nitric solution}

Regarding the results obtained in nitric leaching, these follow a similar behavior in trend, but lower in terms of REE recovery efficiencies respect to hydrochloric leaching. The recovery efficiencies for total REE are reported in Figure 11, it is possible to observe that the REE recovery efficiencies are higher for the $\mathrm{ABC}$ case. The maximum global recovery of these elements was $40.6 \%$. Regarding the significant elements, the one with the best recoveries corresponds to $\mathrm{La}$ and $\mathrm{Ce}$, with a maximum efficiency of $47.2 \%$ and $44.7 \%$, respectively. For Y the results are close to the total REE in all test combinations and showing a different behavior to the case of hydrochloric leaching, the Sc presents quite low levels of recovery, that is, it does not have a similar behavior for a nitric solution.

Additionally, the influence of the main effects was determined separately, Figure 12, where it is possible to observe that the factors that present a greater influence within the total REE recovery efficiencies correspond to (L/S) ratio and with a lower influence of temperature and acid concentration, this behavior can be generated by similar arguments to those described for the case of hydrochloric acid, only that the interaction of the acid molecule is less strong with the REE. Regarding the interaction of the main effects for the recovery of total REE, Figure 13, it is

Table 3. Rare earth elements concentration (ppm) in PLS, test ABC, Hydrochloric solution.

\begin{tabular}{cccccccccc}
\hline & \multicolumn{8}{c}{ REE concentration (ppm); PLS } \\
\hline Element & Sc & Y & La & Ce & Pr & Nd & Sm & Eu & Gd \\
\hline Concentration & 5.43 & 14.10 & 29.10 & 26.5 & 1.54 & 3.43 & 0.62 & 0.10 & 1.09 \\
\hline Element & Tb & Dy & Ho & Tm & Er & Yb & Lu & REE total \\
\hline Concentration & 0.26 & 2.05 & 0.52 & 2.40 & 0.44 & 3.69 & 0.52 & 92.10
\end{tabular}

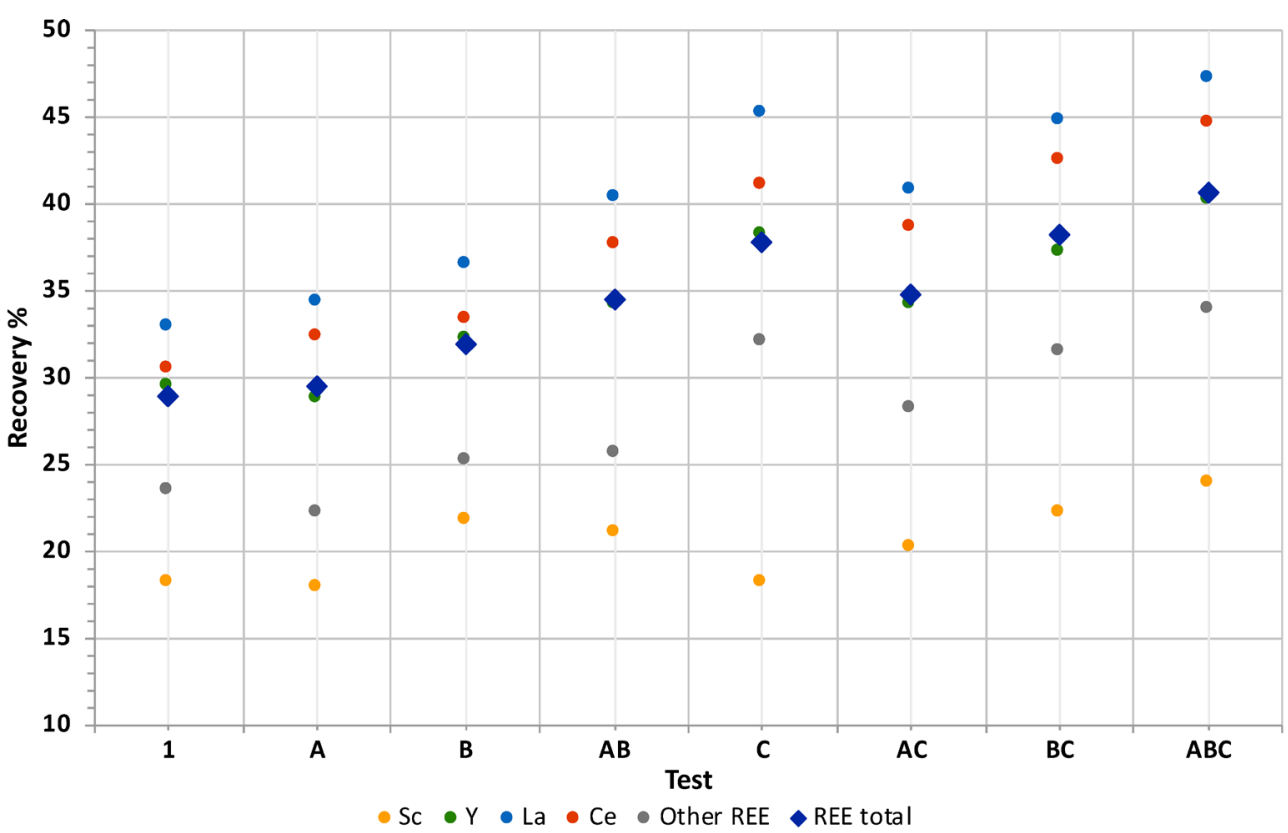

Figure 11. REE recovery efficiencies from mining tail 1, by leaching with nitric solution. 


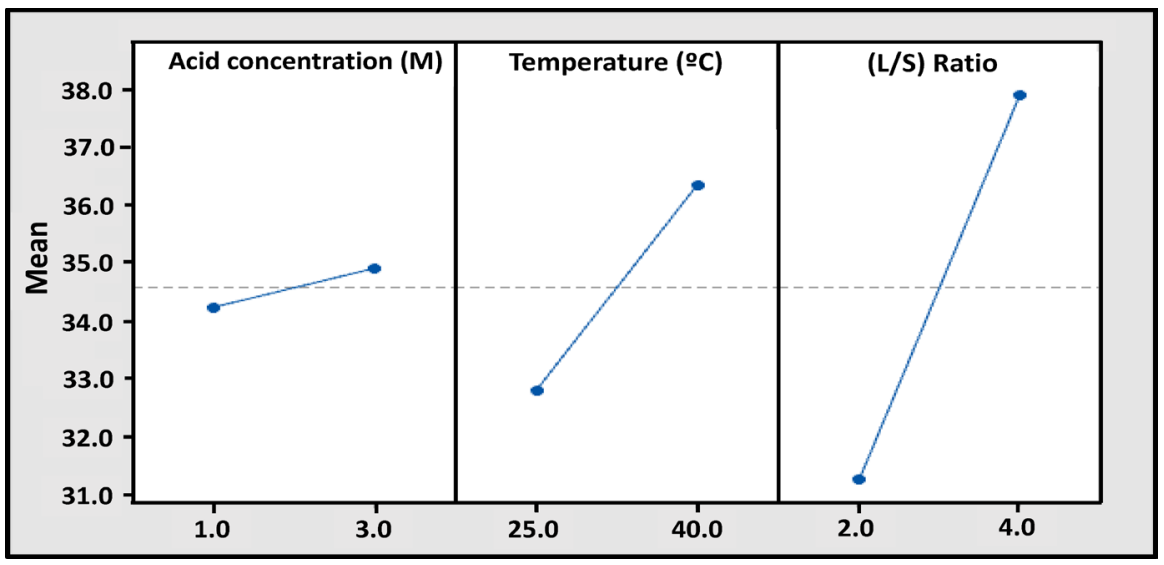

Figure 12. Individual factor effect in REE total recovery, Nitric solution.

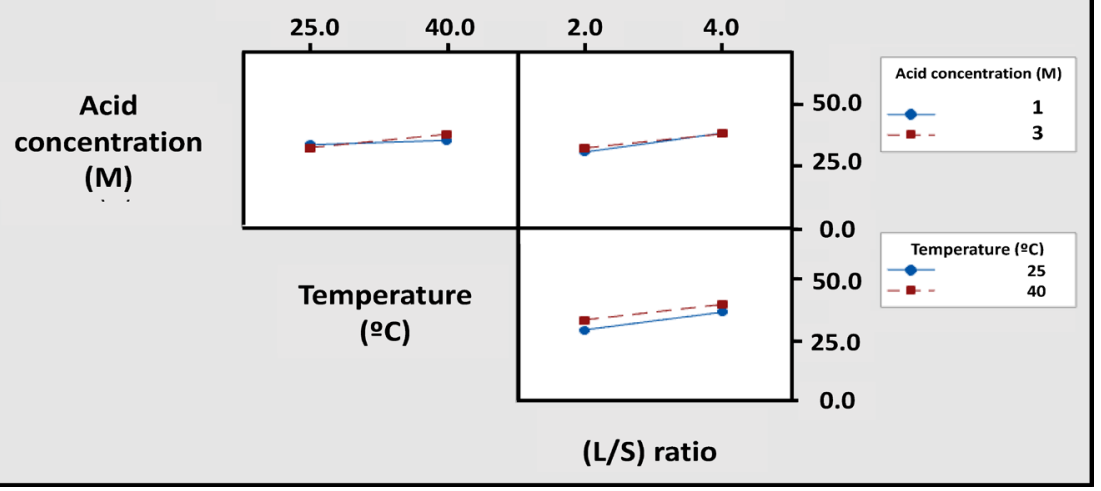

Figure 13. Interaction of main effects in total REE efficiency recovery, Nitric solution.

Table 4. Rare earth elements concentration (ppm) in PLS, test ABC, Nitric solution.

\begin{tabular}{cccccccccc}
\hline & \multicolumn{10}{c}{ REE concentration (ppm); PLS } \\
\hline Element & $\mathrm{Sc}$ & $\mathrm{Y}$ & $\mathrm{La}$ & $\mathrm{Ce}$ & $\mathrm{Pr}$ & $\mathrm{Nd}$ & $\mathrm{Sm}$ & $\mathrm{Eu}$ & $\mathrm{Gd}$ \\
\hline Concentration & 3.87 & 9.12 & 18.20 & 17.00 & 0.89 & 2.06 & 0.34 & 0.10 & 0.67 \\
\hline Element & $\mathrm{Tb}$ & $\mathrm{Dy}$ & $\mathrm{Ho}$ & $\mathrm{Er}$ & $\mathrm{Tm}$ & $\mathrm{Yb}$ & $\mathrm{Lu}$ & $\mathrm{REE}$ total & \\
\hline Concentration & 0.10 & 1.23 & 0.27 & 1.45 & 0.23 & 2.27 & 0.27 & 58.07 & \\
\hline
\end{tabular}

possible to observe that the interaction between $(\mathrm{L} / \mathrm{S})$ ratio and temperature is the one that presents a greater increase in efficiency, which are not highly significant. Table 4 shows the REE concentrations of the PLS obtained in ABC test, with the best recovery efficiency.

The comparison of results for the total REE recovery efficiency is shown in Figure 14, where it is possible to observe that for all the combinations the values obtained by hydrochloric leaching are higher and present a greater range of variation between them, with difference from the REE recoveries with nitric solution, where there is no significant variation considering the lower values of operational parameters (e.g.: test 1) with respect to the higher ones (e.g.: test $A B C$ ).

Additionally, the behavior of the REE was determined as a function of the 
leaching time, considering the operational parameters used in the tests where the best results were obtained, correspond to $\mathrm{ABC}$ test.

\subsection{Leaching Reaction Time}

The results obtained are those shown in Figure 15, where it is possible to observe the recovery differences as a function of time for the two types of acid solutions, where after $4(\mathrm{~h})$ of leaching the total REE recovery efficiencies they remain with little variation, which is complemented by the results of the Iso-pH tests, where after $6(\mathrm{~h})$ there is no acid consumption by the mining tail 1 . This is possibly due to the fact that with the passage of time the rate of the reaction decreases because the reaction surface is increasingly distant from the surface of

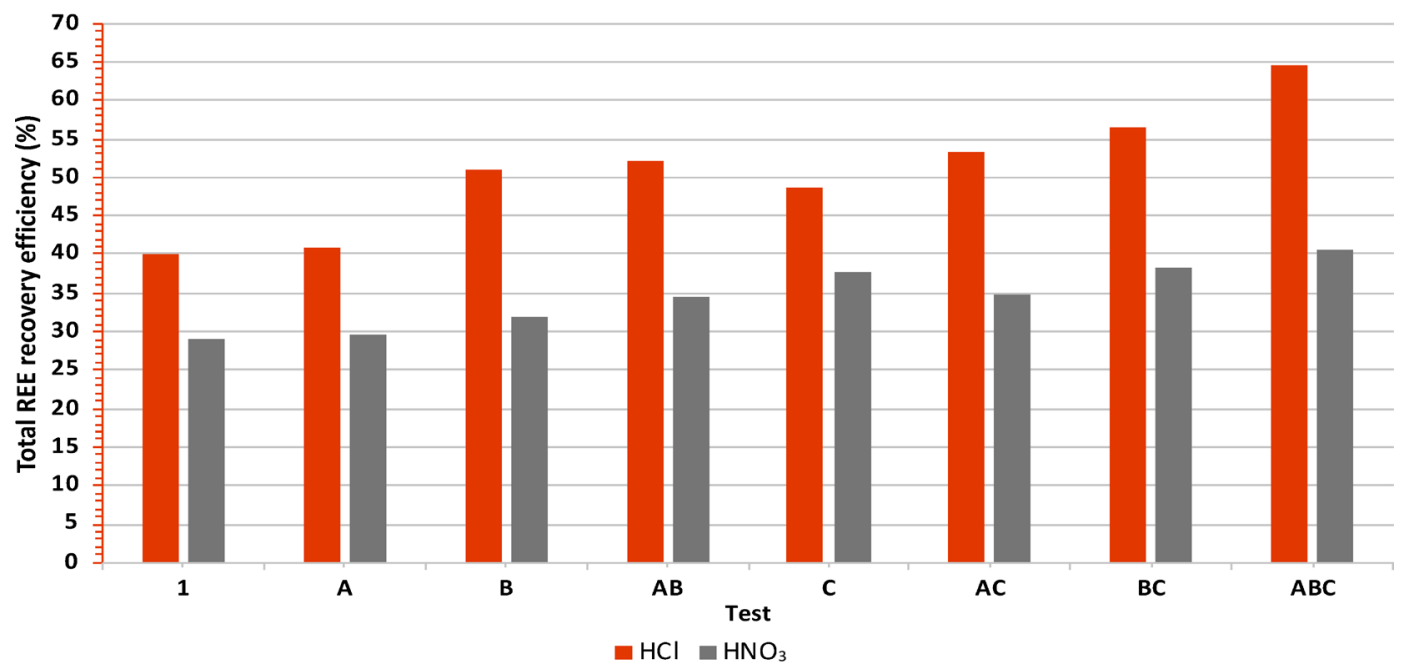

Figure 14. Total REE recovery efficiencies from mining tail 1, by leaching with hydrochloric and nitric solutions, separately.

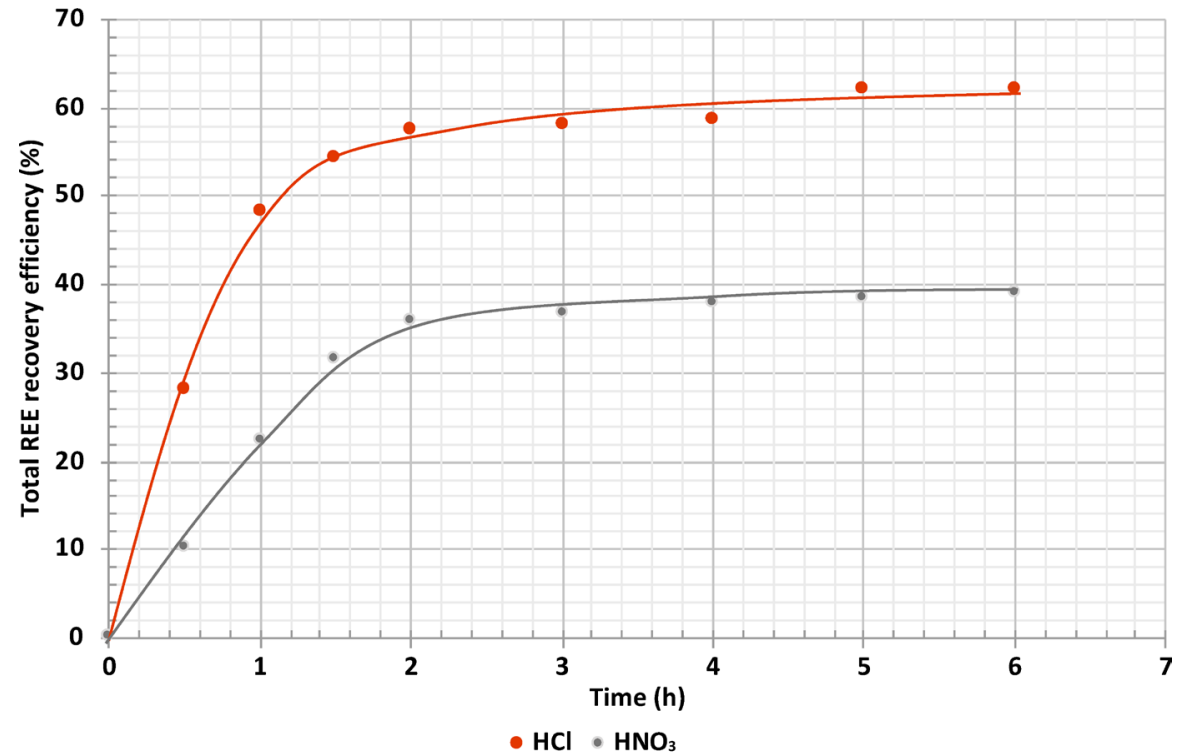

Figure 15. REE recovery efficiencies as function of time, hydrochloric and nitric solution, ABC test. 
the particle and the reactants and products take longer to move inside the particle.

\subsection{REE Recovered per Ton of Mining Tail 1 Treated}

In order to determine the amount of REE recovered with respect to the initial amount of mining tail 1 leached, the values shown in Table 5 were determined, obtained through mass balances of these elements, where it is possible to observe that there is the same trend that in the recovery efficiencies, that is, the higher ratios (kg REE/ton mining tail 1) are obtained for hydrochloric solutions, where the maximum value corresponds to 0.355 (kg REE/ton mining tail 1), for the test $\mathrm{ABC}$, which includes the highest values of operational variables. In the case of nitric solutions, the best result is 0.224 ( $\mathrm{kg} \mathrm{REE} /$ ton mining tail 1 ) for the same combination as the previous solution. These results are consistent with the values reported in the tables and graphs above, such as the influence of the variables studied on the total REE recovery efficiency.

\subsection{Behavior of Iron in the Leaching Process}

Iron recoveries for the hydrochloric and nitric solution are $21.62 \%$ and $22.51 \%$, respectively, corresponding to concentrations of 1105 (ppm) and 1162 (ppm). These concentrations are significant for the following solvent extraction process, considering that a solution without elements that compete with the REE with the organic extractant is required, so it will be necessary to carry out an intermediate stage to eliminate this element and/or change its oxidation state.

\subsection{Comparison with Other Results}

There are few studies referring to the recovery of REE from these mining waste in Chile and the existing information is confidential or very general, so these results cannot be compared with similar ones, also, each geological and mineralogical composition is different depending on the deposit. Currently in Chile, other recovery studies are being developed for these elements from other types

Table 5. Total REE recovered per tonne of mining tail 1 treated.

\begin{tabular}{ccc}
\hline & Total REE recovered (kg REE/ton mining tail 1) \\
\hline Test & $\mathrm{HCl}$ & $\mathrm{HNO}_{3}$ \\
\hline $\mathbf{1}$ & 0.205 & 0.149 \\
A & 0.214 & 0.147 \\
B & 0.253 & 0.160 \\
AB & 0.262 & 0.171 \\
C & 0.269 & 0.208 \\
AC & 0.295 & 0.189 \\
BC & 0.311 & 0.210 \\
ABC & 0.355 & 0.224 \\
\hline
\end{tabular}


of mining environmental liabilities generated in the copper sulphide treatment process, but this information is not yet available, so it may be compared in the near future. Regarding the recovery of REE from ores, the studies carried out are confidential, but it is possible to ensure that the recovery efficiency for mining environmental liabilities is higher than for ores, possibly due to the elements that hinder selectivity, such as Iron, were previously removed, so that by leaching the mining tail again there are better conditions for the extraction of REE.

\subsection{Industrial and Economic Aspects}

The process developed will be scaled to a pilot level, in order to evaluate the variability of results. The industrial application would be possible through the construction of an operation plant, whose capacity must be defined according to the economic evaluation to be carried out once the complete process for obtaining REE oxide concentrates is developed.

Regardless of whether the acid consumption may be higher or lower than for other elements of value, once the complete production chain has been developed, the overall process can be economically evaluated.

\section{Conclusions}

- The technical feasibility of recovering total REE from mining tail was demonstrated, through the application of hydrometallurgical acid leaching technique by mechanical stirring with hydrochloric and nitric solution.

- The best leaching agent for total REE is a hydrochloric solution, reaching a maximum efficiency of $64.5 \%$, considering the values of operational parameters: hydrochloric acid concentration: $3 \mathrm{M}$, Temperature: $40^{\circ} \mathrm{C}$ and $(\mathrm{L} / \mathrm{S}) \mathrm{ra}-$ tio: 4 , additionally, this solution presented the best recovery values for all the test, compared to the nitric solution, with a maximum efficiency of $40.6 \%$ for the same test.

- The PLS obtained contains a total REE concentration of 92.10 (ppm) and $58.07(\mathrm{ppm})$ for hydrochloric and nitric solutions, respectively.

- La and Ce present the best individual recoveries compared to the other REE, with a maximum efficiency for a hydrochloric solution of $75.7 \%$ and $70.0 \%$, respectively, and $47.2 \%$ and $44.7 \%$ in the case of a nitric solution.

- The interaction of operational parameters that most influences the recovery of total REE corresponds to the temperature as a whole to the (L/S) ratio, the acid concentration being the one with the least influence, in both cases.

- The acid consumptions for the two types of leaching solutions correspond to: $11(\mathrm{~kg} \mathrm{HCl} /$ ton mining tail 1$)$ and $29\left(\mathrm{~kg} \mathrm{HNO}_{3} /\right.$ ton mining tail 1).

- The best results obtained in determining the amount of REE recovered with respect to the amount of gravel treated corresponds to 0.355 ( $\mathrm{kg} \mathrm{REE} / \mathrm{ton}$ mining tail 1) for hydrochloric solution and 0.224 (kg REE/ton mining tail 1) for nitric solution.

- After 4 (h) of leaching, the total REE recovery efficiencies remain practically 
constant.

- Considering the iron concentrations in the PLS, it is necessary to add an intermediate stage prior to the solvent extraction, to eliminate this element and/or change its oxidation state.

- The importance of the development of this process is in order to analyze the possibility of generating greater diversity in the Chilean mining matrix, in addition to supporting a circular economy, through a second life for this type of mining waste. $\mathrm{R} \& \mathrm{D}$ activities of the later stages are currently being carried out, which will help to define the existence of economic feasibility regarding the treatment of mining tails with the presence of REE.

\section{Conflicts of Interest}

The authors declare no conflicts of interest regarding the publication of this paper.

\section{References}

[1] Castor, S.B. and Hedrick, J.B. (2006) Rare Earth Elements.

[2] COCHILCO (2016) Current Situation of the Rare Earth Market and Its Potential in Chile.

[3] Castor, S.B. and Hedrick, J.B. (2006) Industrial Minerals Volume, 7th Edition, Society for Mining, Metallurgy and Exploration, Littleton, Colorado, 769-792.

[4] Gschneidner, K. and Pecharsky, V. (2019) Rare-Earth Element.

[5] Chilean Nuclear Energy Commission-CChEN (1985) Background on the Existence of Thorium and Rare Earths in Some Sectors of the Country.

[6] Alarcon, B. (2014). Petro-Chalcographic Microscopic Study of Polished Samples "Sierra Indiana; Quebrada del Desierto and Carmen Norte".

[7] Cáceres, G. (2007) Hydrometallurgy and Electrometallurgy, 63-69.

[8] Beckel, J. (2000) The Hydrometallurgical Heap Leaching Process and the Development of Copper Mining in Chile.

[9] Domic, E. (2001) Hydrometallurgy: Fundamentals, Processes and Applications.

[10] Montealegre, R. (1971) Exp. Design with Applications to Extractive Metallurgy.

[11] Cárdenas, F., Diaz, M., Guajardo, C. and Oliva, M. (2010) Leaching of Minerals through Piles and Vats. 